\title{
Effects of Location-Specific Meteorological Factors on COVID-19 Daily Infection in a Tropical Climate: A Case of Kuala Lumpur, Malaysia
}

\author{
Ezekiel Kaura Makama $\mathbb{D D}^{1,2}$ and Hwee San Lim $\left.{ }^{1}\right)^{1}$ \\ ${ }^{1}$ School of Physics, Universiti Sains Malaysia, 11800 USM, Pulau Pinang, Malaysia \\ ${ }^{2}$ Department of Physics, University of Jos, PMB 2084, Jos, Nigeria \\ Correspondence should be addressed to Hwee San Lim; hslim@usm.my
}

Received 11 December 2020; Accepted 19 March 2021; Published 10 April 2021

Academic Editor: Pedro Jiménez-Guerrero

Copyright (C) 2021 Ezekiel Kaura Makama and Hwee San Lim. This is an open access article distributed under the Creative Commons Attribution License, which permits unrestricted use, distribution, and reproduction in any medium, provided the original work is properly cited.

\begin{abstract}
Insufficient information on the novel coronavirus (COVID-19) has made it more difficult for the world to tackle its continuous implosion. Meteorological and environmental factors, in both laboratory and epidemiological studies, have been reported to affect the survival and transmission of the virus. In this study, the possible effects of location-specific meteorological parameters in a tropical climate on new daily COVID-19 infection (NDI) are investigated in Kuala Lumpur from 14 March 2020 to 31 August 2020. A generalized additive model (GAM) was imposed on ambient temperature ( $T$ ) and absolute humidity (AH) to explore their nonlinear relationship with NDI. Piecewise linear regression was then used to further discern the relationships below and above the threshold values of both $T$ and AH. The relationship between $T$ and NDI, which was linear and statistically significant for $T>29.7^{\circ} \mathrm{C}$, showed that each unit rise in temperature increases NDI by about $3.210 \%$ (CI: $1.372-7.976$ ). AH had a more pronounced linear association with NDI for $\mathrm{AH} \leq 22.6 \mathrm{~g} / \mathrm{m}^{3}$ but tended to flatten the exposure-response curve above this value. A $1 \mathrm{~g} / \mathrm{m}^{3}$ increase in AH increases NDI by 3.807\% (CI: 2.064-5.732). Generally, the results indicated a positive association between $T$ and NDI, particularly above $29.7^{\circ} \mathrm{C}$, while the association with $\mathrm{AH}$ showed a stronger positive relationship below $22.6 \mathrm{~g} / \mathrm{m}^{3}$. The implication of this is that COVID-19 could not be suppressed on account of warmer weather as such public health interventions remain imperative.
\end{abstract}

\section{Introduction}

Earlier in 2020, cases of a novel coronavirus were witnessed across China, after which the World Health Organization (WHO), on 31 December 2019, announced it was in receipt of information on an epidemic with unidentified etiology, originating from Wuhan, China $[1,2]$. The novel disease, which is associated with the Severe Acute Respiratory Syndrome Coronavirus 2 (SARS-CoV-2), is acknowledged to be highly infectious with consequent public health emergencies. On March 11, 2020, WHO declared SARS-CoV-2 a pandemic due to its high transmissive nature with increased global mobility and officially renamed it COVID-19 [3].

COVID-19 is believed to be transmitted directly from a human to another through respiratory droplets from an infected person (sneezing, coughing, laughing, and, to a large extent, talking) to a healthy person within a range of one metre. A healthy person can also be indirectly infected via contaminated surfaces $[1,4,5]$. The maintenance of social distancing of at least one metre, the avoidance of nose-, mouth-, and eye-touching, and frequent handwashing/sanitizing are, therefore, important steps to mitigate the infection rate [3]. According to clinical diagnosis, COVID-19 patients present symptoms similar to other coronaviruses like severe acute respiratory syndrome (SARS) and Middle East Respiratory Syndrome (MERS) [6]. Although it is widely acknowledged that COVID-19 is transmitted through human respiratory droplets and direct contact, the potential for viral aerosol transmission and the role of weather parameters is an ongoing debate. 
Many studies have associated the spread of COVID-19 with a wide range of factors, among which are weather-related conditions [7-10], including environmental factors such as air pollution index (API) $[11,12]$. The survival and transmission of the virus by droplets from infected persons are considered to be optimal in dry and cold weather conditions [13]. Studies investigating the effects of meteorological conditions on COVID-19 transmission since the beginning of the year 2020 have largely been conducted in China [14, 15], Iran [16], Europe, and the United States of America [17]. These reports and others have contradictory conclusions on the relationship between meteorological factors and COVID-19 transmission. For instance, Liu et al. [14], based on data from 130 Chinese cities between 20 January and 2 March 2020, concluded that lower temperatures and humidity favor its transmission. However, Xie and Zhu [15], who investigated the relationship between daily mean temperature and newly confirmed COVID-19 cases in many cities in China, from 23 January to 29 February 2020, reported no evidence to suggest that case counts will decline in warm weather. Yao et al. [18], on the other hand, using the cumulative confirmed cases for 224 Chinese cities, as of 9 March 2020, claimed the nonexistence of correlation between COVID-19 and temperature or UV radiation. However, Bukhari and Jameel [17] analyzed the patterns of local weather of the global regions affected by COVID-19 and reported that most of the regions were within a certain range of temperature and absolute humidity. This is corroborated by Gupta et al. [8] who studied the effect of weather on COVID-19 in the United States (US) between 1 January and 9 April 2020. Temperature and absolute humidity have generally been reported as crucial weather indices associated with the spread of COVID-19, e.g. [8, 17].

Apart from the contradictory results on weather-COVID-19 relationship, it can be argued that the reported association could differ in tropical climates where both temperature and humidity are almost uniformly high all year round with consequent low variations. More so, the studies above covered very short periods of investigation, which has the tendency to impair the outcome of these investigations. Higher rates of COVID-19 in countries like Iran, Italy, and South Korea and in some states in the US share a similar temperature range of between 3 and $10^{\circ} \mathrm{C}$ $[8,17]$ with Hubei in China, the origin of the disease. The lower number of COVID-19 cases in Southeast Asian countries (e.g., Malaysia, Singapore, and Thailand) is attributed to warmer temperatures in the region [17]. It could, therefore, be inferred that, besides mobility and quarantining, other factors are inimical to rising cases of COVID-19 in a location.

In this study, the effects of location-specific weather parameters on new daily COVID-19 confirmed cases in Malaysia are explored. This is motivated by the significant differences in the growth rate of the disease found in different countries and cities, which is mostly attributed to different climatic features. More so, very few evaluations between weather parameters and the evolution of COVID-19 exist for the tropical climate regions [9, 11, 19]. It is imperative, therefore, to investigate if tropical weather parameters slow or aggravate the spread of the virus. The study specifically explores the association of temperature $(T)$ and absolute humidity (AH) with new daily confirmed COVID-19 infections (NDI) in Kuala Lumpur. The choice of the study area is informed by its tropical location, higher cases of the disease, and its population density.

\section{Data and Methods}

2.1. Study Area. The first COVID-19 cases in Malaysia were recorded on 25 January 2020 in Johor Bharu, when some foreigners, whose destination was traced back to China [20], were symptomatic. The infection remained very low and largely confined to imported cases, not until the emergent of localized clusters, which spiked due to a religious gathering in Kuala Lumpur earlier in March 2020. The total number of infections in Malaysia, from 14 March 2020 to 31 August 2020, stood at 9,353, with Kuala Lumpur, Selangor, Negeri Sembilan, Johor, Sarawak, and Sabah recording higher cases in that order. Kuala Lumpur along with areas mentioned had 7,963 cumulative infections, representing over $85 \%$ of confirmed cases in Malaysia within this period (see Figure 1).

Kuala Lumpur, the capital city of Malaysia, is in west-central Peninsular Malaysia on latitude $3.141^{\circ} \mathrm{N}$ and longitude $101.687^{\circ} \mathrm{E}$. It is the country's largest urban area and its cultural, commercial, and transportation center. The climate is Af (tropical rainforest) under the Köppen climate classification, with high temperatures and humidity that vary little throughout the year. The arithmetic means of maximum, average, and minimum temperatures are, respectively, 35,29 , and $23.4^{\circ} \mathrm{C}$, with an average relative humidity of $80 \%$. The area receives about 2,400 mm of rain annually, with June and July as the driest months. Being a capital city, Kuala Lumpur is the main destination for investors, job seekers, and tourists. It is therefore the most densely populated city in Malaysia, with about 8 million people residing within $243 \mathrm{~km}^{2}$, which represents $3.14 \%$ annual growth rate (https:// worldpopulationreview.com/world-cities/kuala-lumpurpopulation). Analyzing the spread of COVID-19 transmission in relation to weather and environmental variables in Kuala Lumpur is important because of its economic relevance and population density. More so, Auler et al. [11] and Bashir et al. [12] have emphasized on the importance of evaluating weather parameters in a densely populated environment. As of 31 August 2020, the cumulative COVID-19 confirmed infection in Kuala Lumpur stood at 2,587, the highest in the country as shown earlier in Figure 1.

2.2. Data. Daily records of mean ambient temperature $\left({ }^{\circ} \mathrm{C}\right)$, wind speed $(\mathrm{m} / \mathrm{s})$, and relative humidity $(\%)$, for the period 14 March to 31 August 2020, were retrieved from the archives of Weather Underground, available online at http:// www.wunderground.com/. This popular and reliable online resource for meteorological data has been used extensively for atmospheric research applications [7, 19, 21, 22]. AH, 


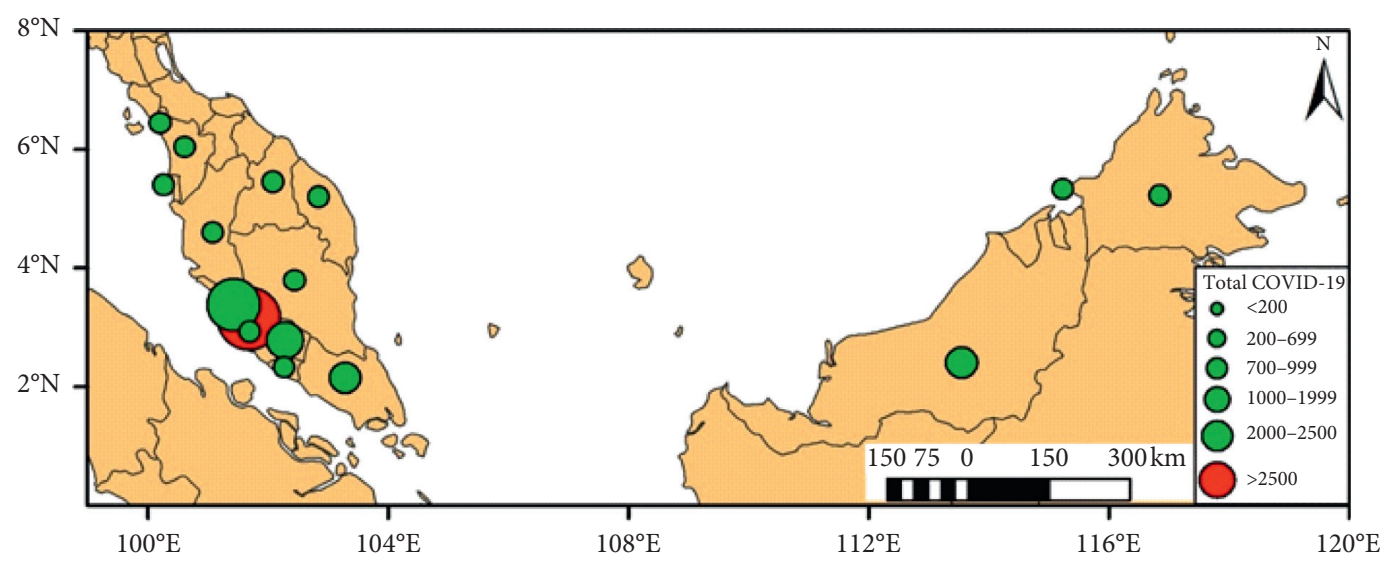

Figure 1: COVID-19 cumulative confirmed cases across states and cities in Malaysia as of 31 August 2020. Kuala Lumpur's cumulative case is classified as the red disc.

which defines the mass of water vapor per volume of air ( $\mathrm{g} /$ $\mathrm{m}^{3}$ ), was considered because it is regarded as a better indicator of humidity in acute health effects $[8,23,24]$. Shaman and Kohn [24] reported that whereas AH can, respectively, explain $50 \%$ and $90 \%$ variations in influenza virus transmission and its survival, $H$ can only explain $12 \%$ and $36 \%$ and that the epidemic influenza usually peaks during winter when low AH maximizes. Some studies, therefore, support the epidemiological notion that low $\mathrm{AH}$ (cold and dry weather) promotes the growth of dropletmediated virus, while higher $\mathrm{AH}$ (warm and humid conditions) attenuates the viral transmission [24, 25]. Daily mean value of $\mathrm{AH}\left(\mathrm{g} / \mathrm{m}^{3}\right)$ was, therefore, computed for the study period using Clausius-Clapeyron relationship given in equation (1):

$$
\mathrm{AH}=2.1674 H \frac{6.112 e^{(17.67 T / T+243.5)}}{T+273.15},
$$

where $T$ and $H$ are the temperature and relative humidity, respectively.

Hourly API data, which is based on mean concentrations of $\mathrm{PM}_{10}, \mathrm{O}_{3}, \mathrm{CO}, \mathrm{SO}_{2}$, and $\mathrm{NO}_{2}$, was obtained from the air quality division of the Malaysian Department of Environment. The hourly API data for Kuala Lumpur, from the 2 background monitoring stations (Batu Muda and Cheras), covering the study period, was extracted and rescaled to daily means for compatibility with COVID-19 daily cases. Secondary data on COVID-19 cases (cumulative and daily) for the states/cities in Malaysia was obtained from the official website of the Ministry of Health, Malaysia: http://covid-19. moh.gov.my/, from which the data for Kuala Lumpur were extracted.

2.3. Statistical Evaluation. Descriptive analysis was performed for all datasets. Since the main objective of this study is to explore the association of COVID-19 new daily infection, hereafter NDI, with weather variables, Spearman correlation, a nonparametric test, was deployed. Spearman's rank correlation coefficient or rho $\left(r_{\mathrm{s}}\right)$ determines the direction and strength of the monotonic relationship between two variables and can be estimated using equation (2):

$$
r_{s}=1-\frac{6 \sum d_{i}^{2}}{n\left(n^{2}-1\right)},
$$

where $d_{i}$ is the difference between the two ranks of each observation and $n$ is the number of observations. A perfectly positive or negative Spearman's correlation coefficient is obtained when $r_{s}= \pm 1$. We used the generalized additive model (GAM) to study the effects of weather factors on NDI. GAM is a semiparametric extension of the generalized linear model, often used to explore the nonlinear relationships between weather parameters and health-related issues $[15,26,27]$. Since the effect of weather on COVID-19 could last several days [20], we considered a moving average approach to accommodate the cumulative lag. The moving average lag effect (lag0-7, lag0-14, lag0-21, and lag0-28) of $T$ and AH on NDI was, therefore, examined.

GAM with a Gaussian distribution link function, in which the basic model for NDI was first built without the meteorological variables, was implemented. We incorporated smoothed spline functions of time, which accommodates nonlinear and nonmonotonic patterns between NDI and time, thereby offering a flexible modelling tool. A measure of how well the model fitted the data was determined by Akaike's information criterion. The penalized smoothing spline function was used to control the effects of confounding factors like time trends, day of week (DoW), and API, after which the meteorological factors were introduced and their effects on NDI analyzed in accordance with some time-series studies $[27,28]$. The model was defined in equation (3):

$$
\begin{aligned}
\log \mathbb{E}(Y)_{t}= & \beta_{0}+\beta X_{t}+s(t, k=d f+1) \\
& +s(\mathrm{API}, k=d f+1)+\text { DoW, }
\end{aligned}
$$

where $\mathbb{E}\left(Y_{t}\right)$ is the expected number of NDI, $Y_{t}$ is the NDI for day $t$, and $t$ is the day of observation. $\beta_{0}$ and $\beta$ are the intercept and coefficient of regression, $X_{t}$ is the value of the 
meteorological parameter on day $t$, and $s(\cdot)$ is the smooth function of time and API variables. The statistical analyses were two-sided at a $95 \%$ interval and were performed using the statistical software $R$ (version 3.5.3) with $\mathrm{mgcv}$ (version 1.8-27) package. The effect estimates per one unit increase in the meteorological variables associated with NDI were expressed as percentage changes with their $95 \%$ confidence intervals (CIs).

\section{Results and Discussion}

3.1. Descriptive Analysis of COVID-19 Cases and Weather Variables. Daily variations of weather parameters used in this study, from 14 March to 31 August 2020 and their descriptive statistics, are, respectively, presented in Figure 2 and Table 1. Within this period, a cumulative number of 2,587 confirmed cases of COVID-19 were recorded in the study area, during which temperature ranged from $25.7^{\circ} \mathrm{C}$ to $33.4^{\circ} \mathrm{C}$ with an average of $29.50 \pm 1.13^{\circ} \mathrm{C}$ and a mean daily variation of $7.7 \pm 1.59^{\circ} \mathrm{C}$. The narrow variation in temperature is to be expected in a tropical climate, where seasonal distinction is not as conspicuous as obtained in the mid and high latitude regions. Wind speed was between $0.01 \pm 0.04$ and $4.81 \pm 1.15 \mathrm{~m} / \mathrm{s}$ with an average speed of $1.56 \pm 0.47 \mathrm{~m} / \mathrm{s}$. Large daily variation $\left(20.8 \mathrm{~g} / \mathrm{m}^{3}\right)$ of absolute humidity was obtained, where the means were confined within $13.90 \pm 2.06$ and $34.7 \pm 2.96 \mathrm{~g} / \mathrm{m}^{3}$, with the overall average being $22.7 \pm 1.06 \mathrm{~g} / \mathrm{m}^{3}$. Kuala Lumpur, within the study period, presented moderate API as seen in Table 1, with maximum, average, and minimum daily means being 69, 55, and 38, respectively. Although the air quality, within the period of investigation, was generally moderate in the area, the values were still higher than those obtained in most cities across Malaysia (not shown).

Cumulative infections and NDI in Kuala Lumpur, from 14 March to 31 August, are shown in Figure 2(a). NDI showed very high variation probably due to subnotification cases of the pandemic in Malaysia. This conclusion is borne from the fact that there was no statistical mode for the registered NDI as shown earlier in Table 1. The number of new cases followed the same trend with the cumulative infections until 13 April when the trend became distorted, particularly from 4 June to 31August, except for some spikes on 25 May and 3 June. For instance, the highest cumulative case on 31 August matched zero new daily infections. Daily infection peaked on 3 June 2020, with 204 NDI, resulting in 2,288 cumulative cases, after which the number dropped drastically flattening the cumulative curve. The drop in reported infection is perhaps due to measures adopted by the Malaysian authorities, during which quarantining and public lockdown were enforced, leading to the declaration of movement control order (MCO). As of 31 August 2020, there was no new infection and cumulative infection was 2,587 . The relatively large number of COVID-19 cases in Kuala Lumpur, being the main economic hub for investors, job seekers, and tourists, is to be expected due to its dense human population [17, 29] among other factors like weather.
3.2. Relationship between Meteorological/Environmental Variables and NDI. Temperature, wind speed, absolute humidity, and air pollution index, from 14 March 2020 to 31 August 2020, have been correlated with NDI in Kuala Lumpur. Although the explanatory variables (meteorological and environmental) showed normal univariate distribution based on their kurtosis and asymmetry seen earlier in Table 1, which were within \pm 2 [30], we opted for a nonparametric approach to avoid possible autocorrelation issue. Spearman's rank correlation test was, therefore, imposed on the variables, and the results are summarized in Table 2. T and $\mathrm{AH}$ showed respective significant positive correlations of 0.38 and 0.64 with NDI at the $1 \%$ level. Strong negative association was, however, observed for $u(-0.36)$ and API $(-0.35)$ also at the $1 \%$ level.

3.3. Effects of Meteorological Variables on NDI. The relationship between meteorological variables and NDI, after controlling the effects of API and $u$, is shown in the exposure-response curves depicted in Figure 3. Generally, the relationship between $T$ and NDI, seen in Figures 3(a), 3(c), $3(\mathrm{e})$, and $3(\mathrm{~g})$, suggests a positive and significant nonlinear association $(p<0.05)$ except for lag0-28, where the association is somewhat linear. A more conspicuous nonlinear influence on NDI was obtained for $\mathrm{AH}$ as seen in Figures 3(b), 3(d), 3(f), and 3(h). The initial positive response of NDI to increase in $\mathrm{AH}$ was linear until at a threshold value of $22.60 \mathrm{~g} / \mathrm{m}^{3}$ when the relationship became nonsignificant, resulting in the observed flattened curve thereafter.

The model was subjected to sensitivity test by altering the degree of freedom $(d f)$ of the penalized smoothing spline function for calendar time as well as changing the $d f$ between 3 and 6 for both Tand AH. Based on the nonlinear GAMs relationship between NDI and the meteorological variables, we carried out piecewise linear regression to further evaluate their effects in this sensitivity analysis. A piecewise linear regression was conducted using the respective threshold values of $29.7^{\circ} \mathrm{C}$ and $22.6 \mathrm{~g} / \mathrm{m}^{3}$ to estimate the effects of $T$ and AH on NDI above and below these knot points. The result of the piecewise regression, after controlling $u$ and API, at the respective break points of $T$ and $\mathrm{AH}$ for all the lags, including their corresponding confidence intervals (CIs) at the $95 \%$ level, is presented in Table 3.

It was observed that a $1^{\circ} \mathrm{C}$ rise in $T$, with its value $\leq 29.7^{\circ} \mathrm{C}$, led to corresponding changes of $1.024 \%$ (CI: $0.721-2.864$ ) and $1.462 \%$ (CI: $0.191-3.170)$ in NDI for lag0-7 and lag0-28, respectively. However, within this temperature range, the positive effect of $T$ on NDI was statistically nonsignificant for lag0-14 and lag0-21. Higher significant and positive responses in NDI for each $1^{\circ} \mathrm{C}$ rise in $T$ were recorded for values above $29.7^{\circ} \mathrm{C}$ in all the lags, with lag0-28 presenting the greatest effect of $3.210 \%$ (CI: 1.372-7.976). The result also showed that the effect of absolute humidity on $\mathrm{NDI}$ at $\mathrm{AH} \leq 22.6 \mathrm{~g} / \mathrm{m}^{3}$ is generally positive and strongly significant at the $95 \%$ level. The greatest effect was observed in lag0-28, with $1 \%$ change in AH resulting in a $3.807 \%$ (CI: 2.064-5.732) increase in NDI. Although the effect of $\mathrm{AH}$ on 


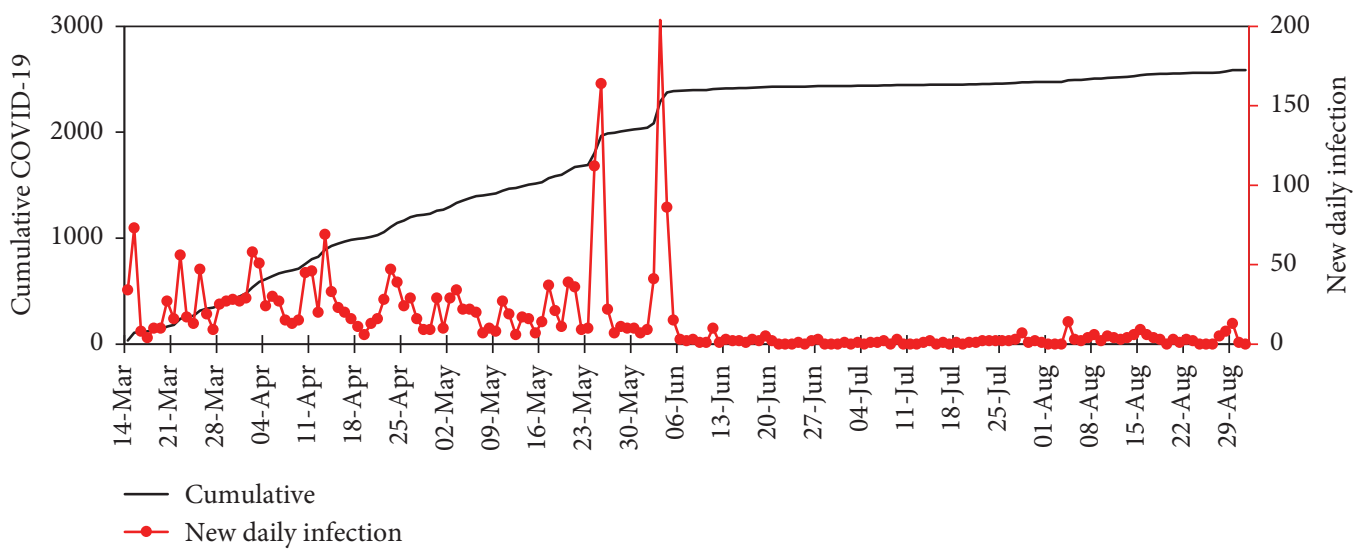

(a)

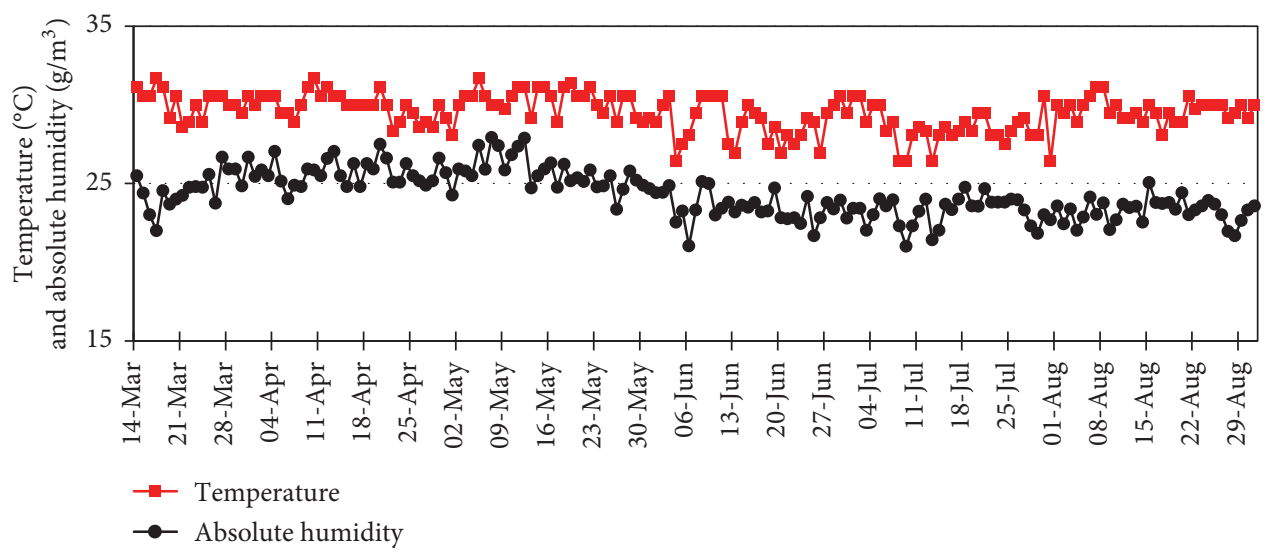

(b)

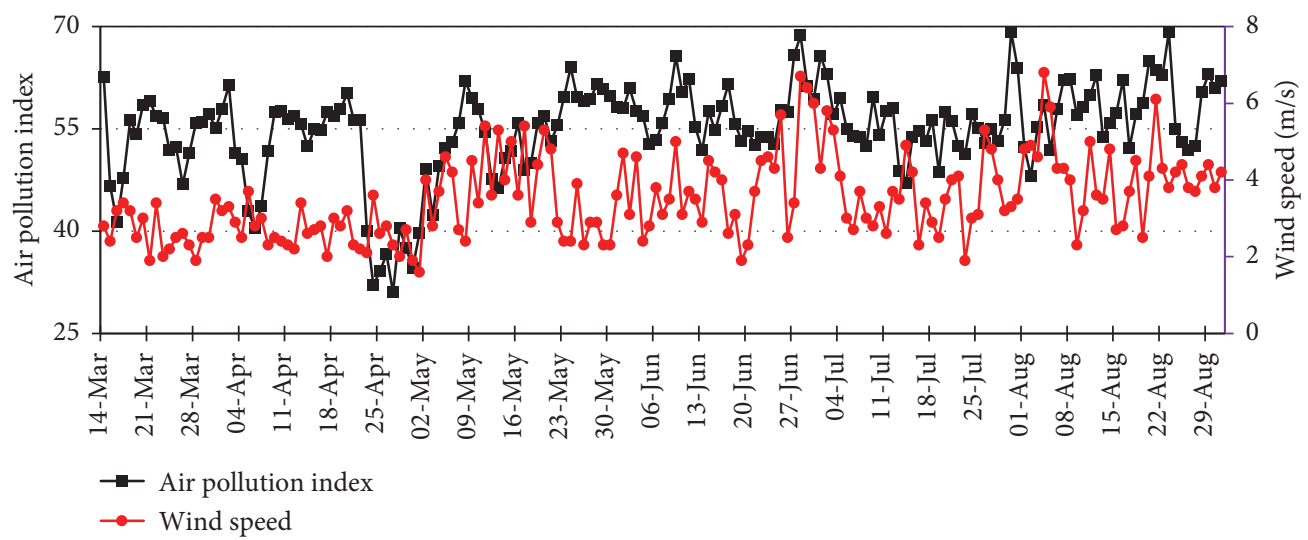

(c)

Figure 2: Daily variation of weather parameters and COVID-19 cases from 14 March to 31 August 2020 for Kuala Lumpur. (a) Cumulative and daily COVID-19 spread, (b) mean temperature and absolute humidity, and (c) wind speed and air pollution index.

Table 1: Descriptive statistics of COVID-19 cases and weather variables in Kuala Lumpur from 14 March 2020 to 31 August 2020.

\begin{tabular}{|c|c|c|c|c|c|c|c|c|c|}
\hline Parameters & Mean \pm SD & Minimum & Maximum & ${ }^{\mathrm{a}} \mathrm{P}(25)$ & Median & $\mathrm{P}(75)$ & Mode & ${ }^{\mathrm{b}}$ Kut. & ${ }^{\mathrm{c}}$ Asy. \\
\hline${ }^{\mathrm{d}} \mathrm{NDI}$ & $15 \pm 25.30$ & 0 & 204 & 2 & 7 & 20 & - & 17.7 & 3.6 \\
\hline Temperature $\left({ }^{\circ} \mathrm{C}\right)$ & $29.5 \pm 1.13$ & 26.39 & 31.67 & 28.90 & 29.72 & 30.6 & 30 & 0.3 & -0.8 \\
\hline Wind speed $(\mathrm{m} / \mathrm{s})$ & $1.56 \pm 0.47$ & 0.72 & 3.04 & 1.16 & 1.52 & 1.88 & 1.03 & 0.7 & 1.0 \\
\hline Absolute humidity $\left(\mathrm{g} / \mathrm{m}^{3}\right)$ & $22.7 \pm 1.06$ & 19.48 & 26 & 21.80 & 22.56 & 23.50 & 22.45 & 0.2 & 1.0 \\
\hline${ }^{\mathrm{e}} \mathrm{API}$ & $54 \pm 6.74$ & 38 & 69 & 50 & 55 & 58 & 47 & 0.5 & -0.2 \\
\hline
\end{tabular}

${ }^{\mathrm{a}}$ Percental. ${ }^{\mathrm{b}}$ Kurtosis,. ${ }^{\mathrm{c}}$ Asymmetry. ${ }^{\mathrm{d}} \mathrm{New}$ daily infection. ${ }^{\mathrm{e}}$ Air pollution index. 
TABLE 2: Summary of Spearman's rank correlation test on the association of new daily COVID-19 cases and weather parameters in Kuala Lumpur from 14 March 2020 to 31 August 2020.

\begin{tabular}{lcccc}
\hline & NDI $\left({ }^{\circ} \mathrm{C}\right)$ & $T\left({ }^{\circ} \mathrm{C}\right)$ & $u(\mathrm{~m} / \mathrm{s})$ & $\mathrm{AH}\left(\mathrm{g} / \mathrm{m}^{3}\right)$ \\
\hline New daily infection (NDI) & 1.00 & & & \\
Temperature (T) & $0.38^{* *}$ & 1.00 & & \\
Wind speed $(u)$ & $-0.36^{* *}$ & 0.12 & 1.00 & 1.00 \\
Absolute humidity (AH) & $0.64^{* *}$ & $0.31^{* *}$ & $-0.43^{* *}$ & $-0.36^{* *}$ \\
Air pollution index (API) & $-0.35^{* *}$ & -0.01 & $0.29^{* *}$ & 1.00 \\
\hline$* *$ & & &
\end{tabular}

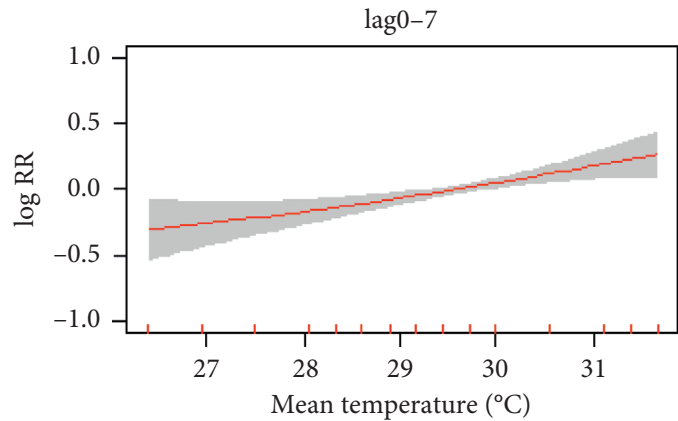

(a)

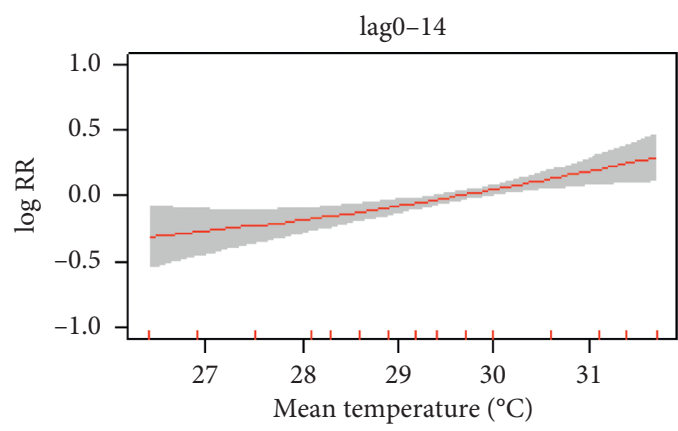

(c)

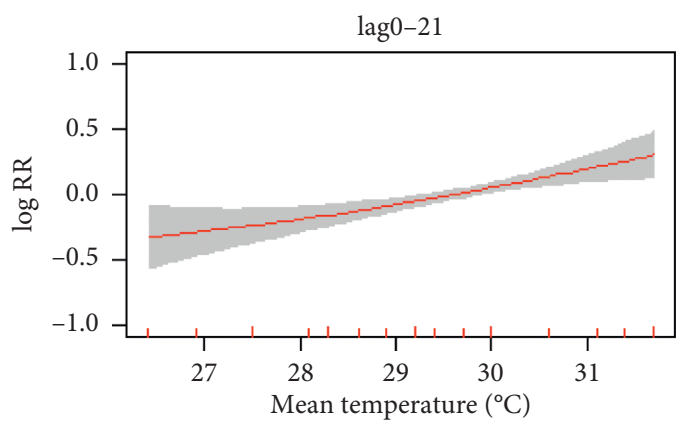

(e)

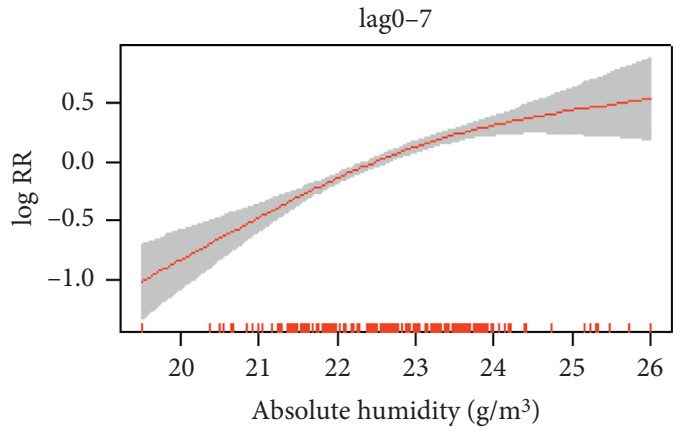

(b)

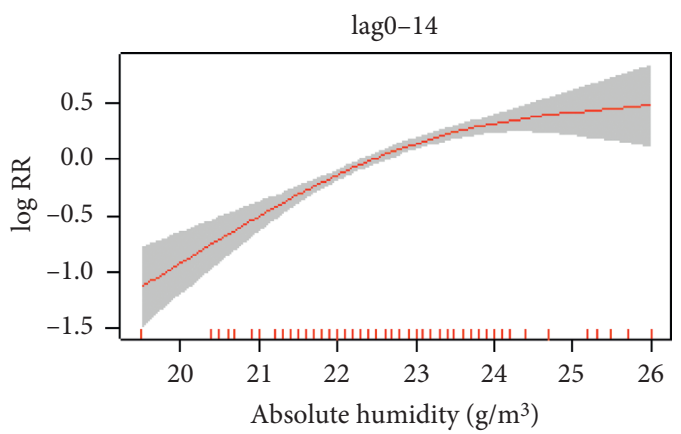

(d)

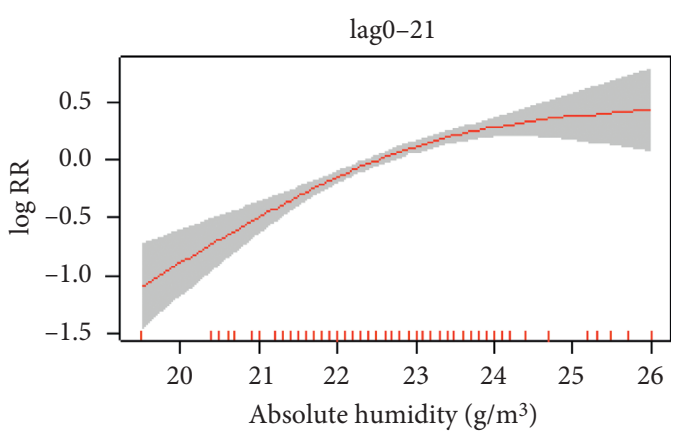

(f)

Figure 3: Continued. 


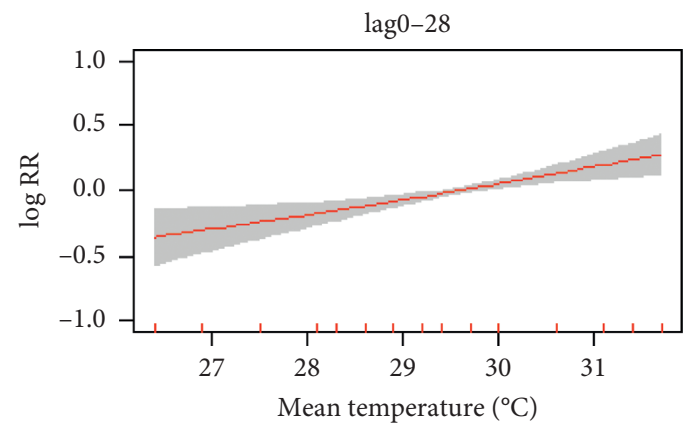

(g)

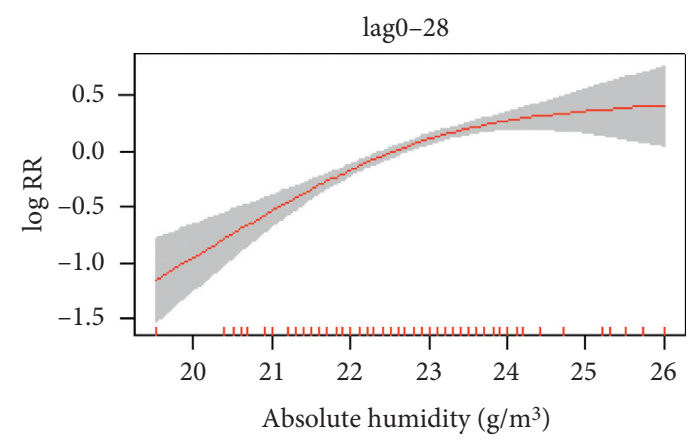

(h)

FIgURE 3: The exposure-response curves for the effects of temperature and absolute humidity on new daily COVID-19 infection. The $x$-axes are the mean temperature and absolute humidity for 7-day, 14-day, 21-day, and 28-day moving average. The $y$-axes indicate relative risk ratio (RR).

TABle 3: The effects of $1^{\circ} \mathrm{C}$ and $1 \mathrm{~g} / \mathrm{m}^{3}$ increases in mean temperature and absolute humidity on new daily COVID-19 infection.

\begin{tabular}{|c|c|c|c|c|}
\hline Lag & Percent change in temperature $(\%)$ & $95 \% \mathrm{CI}$ & Percent change in absolute humidity (\%) & $95 \% \mathrm{CI}$ \\
\hline & \multicolumn{2}{|l|}{$T \leq 29.7^{\circ} \mathrm{C}$} & \multicolumn{2}{|l|}{$\mathrm{AH} \leq 22.6 \mathrm{~g} / \mathrm{m}^{3}$} \\
\hline lag0-7 & $1.024^{*}$ & $0.721-2.864$ & $2.218^{*}$ & $1.057-3.946$ \\
\hline lag0-14 & 0.891 & $0.086-2.004$ & $2.857^{*}$ & $1.721-4.078$ \\
\hline $\operatorname{lag} 0-21$ & 0.783 & $0.014-2.164$ & $2.936^{*}$ & $1.654-4.709$ \\
\hline \multirow[t]{2}{*}{ lag0-28 } & $1.462^{*}$ & $0.191-3.170$ & $3.807^{*}$ & $2.064-5.732$ \\
\hline & \multicolumn{2}{|l|}{$T>29.7^{\circ} \mathrm{C}$} & \multicolumn{2}{|l|}{$\mathrm{AH}>22.6 \mathrm{~g} / \mathrm{m}^{3}$} \\
\hline $\operatorname{lag} 0-7$ & $2.341^{*}$ & $1.085-4.140$ & 0.632 & $0.410-1.364$ \\
\hline lag0-14 & $2.604^{*}$ & $1.326-5.647$ & 0.479 & $0.173-1.042$ \\
\hline lag0-21 & $2.916^{*}$ & $1.017-5.264$ & 0.308 & $0.118-0.501$ \\
\hline lag0-28 & $3.210^{*}$ & $1.372-7.976$ & 0.108 & $0.084-0.401$ \\
\hline
\end{tabular}

${ }^{*} p<0.05$; CI is confidence interval for the change in parameters.

NDI above $22.6 \mathrm{~g} / \mathrm{m}^{3}$ was positive, it was not statistically significant in all the lags.

\section{Discussion}

Previous studies have shown that temperature is an important factor in the spread of human coronaviruses, like MERS-CoV [31], SARS-CoV [32, 33], and COVID-19 $[11,12,15,19]$. We therefore compare our main findings with the results of these studies. In a laboratory study, Chan et al. [32] found that SARS virus could stay for 5 days on a smooth surface at temperature between 22 and $25^{\circ} \mathrm{C}$ with a rapidly lost viability at higher temperatures of $\sim 38^{\circ} \mathrm{C}$. Based on data from Beijing, Guangzhou, Hong Kong, and Taiyuan, Tan et al. [33] also reported that the optimum environmental temperature for SARS virus was between 16 and $28^{\circ} \mathrm{C}$. Similarly, MERS-CoV has been reported to be highly unstable at high temperature [31]. Motivated by the significant differences in COVID-19 infections among different regions, Bukhari and Jameel [17] directly compared the spread of the virus and local environmental conditions globally. They concluded that mean temperatures between 3 and $10^{\circ} \mathrm{C}$ favour the growth rate of the virus, implying that higher temperatures could mitigate the infection, expectedly so, in warmer humid climates. Exploring the relationship between COVID-19 case counts and meteorological parameters in some cities in China, Liu et al. [14] indicated that the infection correlates negatively with temperature. They claimed that every $1^{\circ} \mathrm{C}$ rise in air temperature reduces daily infections by a cumulative relative risk rate of 0.80 . Bashir et al. [12], however, reported a weak but statistically significant positive correlation between COVID-19 new cases and mean temperature in New York City.

Some of the studies cited above alluded to the conclusion that while COVID-19 may thrive in some optimal temperature, warmer temperature should suppress it. In this study, however, negative effect of high temperature on COVID-19 transmission was not observed within the period of evaluation. A possible reason could be that the study area exhibits higher temperature throughout the period of investigation, where the minimum mean value was $\sim 26^{\circ} \mathrm{C}$ with a maximum variation of $7.7^{\circ} \mathrm{C}$. Our result is, however, consistent with similar association reported in Brazil [11] and Singapore [19] which have similar tropical climate. Pani et al. [19] explored the role of weather data on the transmission of COVID-19 in Singapore from 23 January to 31 May 2020 and found it to be positively associated with mean temperature. Also, Auler et al. [11], using principal component analysis, found that soaring viral infection is associated with rising temperatures. Moreover, Xie and Zhu [15] explored the relationship between ambient temperature and daily COVID-19 cases in 122 Chinese cities from 23 January to 29 February 2020 and reported that $1^{\circ} \mathrm{C}$ rise in temperature is associated with a $4.861 \%$ increase in the daily 
confirmed cases. However, they reported a threshold value of $3^{\circ} \mathrm{C}$, beyond which the rate of infection becomes statistically insignificant. The association between temperature and new daily infections in Kuala Lumpur contradicts the findings of Yao et al. [18] who reported no correlation between daily cases of COVID-19 and temperature in China.

$\mathrm{AH}$ has also been reported to associate well with the transmission of coronavirus disease $[8,14,17]$. Bukhari and Jameel [17] analyzed global data from 20 January to 19 March 2020 and reported that COVID-19 transmission is more prevalent in areas where $\mathrm{AH}$ ranges between 3 and $9 \mathrm{~g} /$ $\mathrm{m}^{3}$. Similarly, Gupter et al. [8], using data from 1 January to 9 April 2020 in the US, reported a favorable range for the virus to stabilize as $4<\mathrm{AH}<6 \mathrm{~g} / \mathrm{m}^{3}$. Their conclusions, which implied that areas with high $\mathrm{AH}$ will experience low infections, may not be applicable in tropical regions. More so, the very short period of these investigations has the likelihood of impairing the reported findings. In our case, the significant positive influence of $\mathrm{AH}$ on NDI was nonlinear. The relationship was linear until at $22.60 \mathrm{~g} / \mathrm{m}^{3}$ when a statistically nonsignificant negative response was observed. The implication of the positive correlation between the weather indicators and newly confirmed cases, in this study, indicates that COVID-19 could vanish due to public health interventions and not because of warmer weather. The public or governments could, therefore, not expect warmer climates to suppress this novel virus as canvassed in some instances.

We are, however, not unmindful of some limitations posed to our study. The study considered essentially the association of some weather factors on the evolution of COVID-19 daily infection from 14 March 2020 to 31 August 2020 in Kuala Lumpur, a tropical city. The number of COVID-19 cases in a region/country/state/city is, however, dependent on several other factors including testing rate, population rate, global mobility, governmental policies, ambient air, and surface interactions, among others [17, 34], which are too complex to aggregate in the current study. More so, the weather factors considered in our study only apply to outdoor transmission, even though indoor and direct/indirect transmissions have also been reported. The result presented here is aimed at evaluating possible influence of tropical weather variables on the viability of COVID19. It is suggestive, therefore, that other variables such as surface pressure, dewpoint temperature, water vapor, rainfall, and horizontal wind speed could be included in subsequent evaluation of the spread of the virus in a tropical climate.

\section{Conclusion}

Insufficient information on the novel coronavirus, also known as COVID-19, has made it more difficult for the world to tackle its ongoing implosion. In this study, we presented the possible association between daily community infections and some meteorological parameters. This was done by analyzing data from 14 March 2020 to 31 August 2020, by considering new daily infections and location-specific temperature and absolute humidity over
Kuala Lumpur, a tropical city. Our results showed that new daily COVID-19 confirmed cases correlate significantly with temperature and absolute humidity in a nonlinear relationship. Each $1{ }^{\circ} \mathrm{C}$ and $1 \mathrm{~g} / \mathrm{m}^{3}$ rise in mean temperature and absolute humidity caused up to $3.210 \%$ and $3.807 \%$ increases in the new daily COVID-19 infection, respectively. Within the study period, mean temperature and absolute humidity seemed to favor new daily infections in Kuala Lumpur. This finding is at variance with those reported for temperate regions across the globe, where lower temperatures $\left(3-17^{\circ} \mathrm{C}\right)$ and lower absolute humidity $\left(4-11 \mathrm{~g} / \mathrm{m}^{3}\right)$ are said to enhance the growth rate of the disease $[8,17]$.

\section{Data Availability}

Daily records of meteorological parameters were retrieved from the archives of Weather Underground, available online at https://www.wunderground.com/weather/my/kuala-lumpur.

Hourly air pollution index data, based on mean concentrations of $\mathrm{PM}_{10}, \mathrm{O}_{3}, \mathrm{C}_{\mathrm{O}}, \mathrm{SO}_{2}$, and $\mathrm{NO}_{2}$, were obtained from the air quality division of the Malaysian Department of Environment at http://apims.doe.gov.my/public_v2/api_table.html. Secondary COVID-19 cases for the states/cities were obtained from the official website of the Ministry of Health, Malaysia, at http:// covid-19.moh.gov.my/.

\section{Conflicts of Interest}

The authors declare that they have no conflicts of interest.

\section{Authors' Contributions}

Ezekiel Kaura Makama contributed to data curation, provided software, and wrote the original draft. Hwee San Lim contributed to reviewing and editing, funding acquisition, and project administration.

\section{Acknowledgments}

The authors are grateful to the Malaysia Department of Environment for providing the air pollution index data used in this study. This work was conducted with financial support from RUI grant, Burning in the Southeast Asian Maritime Continent (1001/PFIZIK/8011079), and FRGS, Investigation of the Direct and Semidirect Radiative Effect of Burning Aerosols from AERONET and MPLNET Data over Southeast Asian Maritime Continent (203.PFIZIK.6711608).

\section{Supplementary Materials}

Secondary data on daily COVID-19 infections for Kuala Lumpur, obtained from the official website of the Ministry of Health, Malaysia (http://covid-19.moh.gov.my), along with air pollution index observations, are provided as supplementary data. Daily mean temperature, dewpoint, wind speed, and relative humidity have also been included (Supplementary Materials) 


\section{References}

[1] C. Huang, Y. Wang, X. Li et al., "Clinical features of patients infected with 2019 novel coronavirus in Wuhan, China," The Lancet, vol. 395, pp. 497-506, Article ID 10223, 2020.

[2] P. Zhou, X.-L. Yang, X.-G. Wang et al., "A pneumonia outbreak associated with a new coronavirus of probable bat origin," Nature, vol. 579, no. 7798, pp. 270-273, 2020.

[3] World Health Organization, WHO/Europe | Coronavirus Disease (COVID-19) Outbreak - WHO Announces COVID-19 Outbreak a Pandemic, World Health Organization, Geneva, Switzerland, 2020.

[4] C.-C. Lai, T.-P. Shih, W.-C. Ko, H.-J. Tang, and P.-R. Hsueh, "Severe acute respiratory syndrome coronavirus 2 (SARSCoV-2) and coronavirus disease-2019 (COVID-19): the epidemic and the challenges," International Journal of Antimicrobial Agents, vol. 55, no. 3, Article ID 105924, 2020.

[5] World Health Organization, "Coronavirus disease 2019 (COVID-19)," Situation Report - 66, World Health Organization, Geneva, Switzerland, 2020.

[6] Y. Wang, Y. Wang, Y. Chen, and Q. Qin, "Unique epidemiological and clinical features of the emerging 2019 novel coronavirus pneumonia (COVID-19) implicate special control measures," Journal of Medical Virology, vol. 92, no. 6, pp. 568-576, 2020.

[7] S. S. Gunthe, B. Swain, S. S. Patra, and A. Amte, "Gumpte 2020.pdf," Journal of Public Health from Theory to Practicals, vol. 22, 2020.

[8] S. Gupta, G. S. Raghuwanshi, and A. Chanda, "Effect of weather on COVID-19 spread in the US: a prediction model for India in 2020," Science of The Total Environment, vol. 728, Article ID 138860, 2020.

[9] R. Tosepu, J. Gunawan, D. S. Effendy et al., "Correlation between weather and covid-19 pandemic in Jakarta, Indonesia," Science of the Total Environment, vol. 725, 2020.

[10] N. L. A. Rani, A. Azid, S. I. Khalit, H. Juahir, and M. S. Samsudin, "Air pollution index trend analysis in Malaysia, 2010-15," Polish Journal of Environmental Studies, vol. 27, pp. 801-808, 2018.

[11] A. C. Auler, F. A. M. Cássaro, V. O. Da Silva, and L. F. Pires, "Evidence that high temperatures and intermediate relative humidity might favor the spread of COVID-19 in tropical climate: a case study for the most affected Brazilian cities," Science of the Total Environment, vol. 729, 2020.

[12] M. F. Bashir and B. Ma, "Correlation between climate indicators and COVID-19 pandemic in New York, USA," Science of The Total Environment, vol. 728, Article ID 138835, 2020.

[13] L. M. Casanova, S. Jeon, W. A. Rutala, D. J. Weber, and M. D. Sobsey, "Effects of air temperature and relative humidity on coronavirus survival on surfaces," Applied and Environmental Microbiology, vol. 76, no. 9, pp. 2712-2717, 2010.

[14] J. Liu, J. Zhou, J. Yao et al., "Impact of meteorological factors on the COVID-19 transmission: a multi-city study in China," Science of The Total Environment, vol. 726, Article ID 138513, 2020.

[15] J. Xie and Y. Zhu, "Association between ambient temperature and COVID-19 infection in 122 cities from China," Science of The Total Environment, vol. 724, Article ID 138201, 2020.

[16] M. Ahmadi, A. Sharifi, S. Dorosti, S. Jafarzadeh Ghoushchi, and N. Ghanbari, "Investigation of effective climatology parameters on COVID-19 outbreak in Iran," Science of the Total Environment, vol. 729, 2020.
[17] Q. Bukhari and Y. Jameel, "Will coronavirus pandemic diminish by summer?" SSRN Electron Journal, vol. 66, 2020.

[18] Y. Yao, J. Pan, Z. Liu et al., "No association of COVID-19 transmission with temperature or UV radiation in Chinese cities," European Respiratory Journal, vol. 55, pp. 7-9, 2020.

[19] S. K. Pani, N.-H. Lin, and S. RavindraBabu, "Association of COVID-19 pandemic with meteorological parameters over Singapore," Science of The Total Environment, vol. 740, Article ID 140112, 2020.

[20] A. Elengoe, "COVID-19 outbreak in Malaysia," Osong Public Health and Research Perspectives, vol. 11, no. 3, pp. 93-100, 2020.

[21] M. Kumar, M. P. Raju, R. K. Singh, A. K. Singh, R. S. Singh, and T. Banerjee, "Wintertime characteristics of aerosols over middle Indo-Gangetic Plain: vertical profile, transport and radiative forcing," Atmospheric Research, vol. 183, pp. 268-282, 2017.

[22] L. W. Vos, H. Leijnse, A. Overeem, and R. Uijlenhoet, "Quality control for crowdsourced personal weather stations to enable operational rainfall monitoring," Geophysical Research Letters, vol. 46, no. 15, pp. 8820-8829, 2019.

[23] K. Zhang, Y. Li, J. D. Schwartz, and M. S. O'Neill, "What weather variables are important in predicting heat-related mortality? A new application of statistical learning methods," Environmental Research, vol. 132, pp. 350-359, 2014.

[24] J. Shaman and M. Kohn, "Absolute humidity modulates influenza survival, transmission, and seasonality," Proceedings of the National Academy of Sciences, vol. 106, no. 9, pp. 3243-3248, 2009.

[25] S. Li, "Environmentally mediated transmission models for influenza and the relationships," 2011.

[26] Y. Ma, Y. Zhao, J. Liu et al., "Effects of temperature variation and humidity on the death of COVID-19 in Wuhan, China," Science of The Total Environment, vol. 724, Article ID 138226, 2020.

[27] R. D. Peng, F. Dominici, and T. A. Louis, "Model choice in time series studies of air pollution and mortality," Journal of the Royal Statistical Society: Series A (Statistics in Society), vol. 169, no. 2, pp. 179-203, 2006.

[28] Q. Zeng, G. Li, Y. Cui, G. Jiang, and X. Pan, "Estimating temperature-mortality exposure-response relationships and optimum ambient temperature at the multi-city level of China," International Journal of Environmental Research and Public Health, vol. 13, 2016.

[29] M. Mofijur, I. M. R. Fattah, A. B. M. Saiful Islam, S. M. A. Rahman, and M. A. Chowdhury, "Relationship between climate variables and new daily COVID-19 cases in Dhaka, Bangladesh," Sustainability, vol. 12, no. 20, pp. 1-11, 2020.

[30] D. George and P. Mallery, SPSS for Windows Step by Step: A Simple Guide and Reference. 11.0 Update, Allyn and Bacon, Boston, MA, USA, 4th edition, 2003.

[31] N. van Doremalen, T. Bushmaker, and V. J. Munster, "Stability of Middle East respiratory syndrome coronavirus (MERS-CoV) under different environmental conditions," Eurosurveillance, vol. 18, pp. 1-4, 2013.

[32] K. H. Chan, J. S. M. Peiris, S. Y. Lam, L. L. M. Poon, K. Y. Yuen, and W. H. Seto, "The effects of temperature and relative humidity on the viability of the SARS coronavirus," Advances in Virology, vol. 2011, Article ID 734690, 15 pages, 2011.

[33] J. Tan, L. Mu, J. Huang, S. Yu, B. Chen, and J. Yin, “An initial investigation of the association between the SARS outbreak 
and weather: with the view of the environmental temperature and its variation," Journal of Epidemiology \& Community Health, vol. 59, no. 3, pp. 186-192, 2005.

[34] L. Patients, D. Taylor, A. C. Lindsay, and J. P. Halcox, "Aerosol and surface stability of SARS-COV-2 as compared with SARS-COV-1," 2020. 